\title{
Intentionally induced intestinal barrier dysfunction causes inflammation, affects metabolism, and reduces productivity in lactating Holstein cows
}

\author{
S. K. Kvidera, ${ }^{*}$ M. J. Dickson, ${ }^{*}$ M. Abuajamieh, ${ }^{*}$ D. B. Snider, ${ }^{*}$ M. V. Sanz Fernandez, ${ }^{*}$ J. S. Johnson, ${ }^{*}$ \\ A. F. Keating, ${ }^{*}$ P. J. Gorden, † H. B. Green, $\ddagger$ K. M. Schoenberg, $\ddagger$ and L. H. Baumgard ${ }^{* 1}$ \\ ${ }^{*}$ Department of Animal Science, and \\ †College of Veterinary Medicine, lowa State University, Ames 50011 \\ ‡Elanco Animal Health, Greenfield, IN 46140
}

\section{ABSTRACT}

Study objectives were to evaluate the effects of intentionally reduced intestinal barrier function on productivity, metabolism, and inflammatory indices in otherwise healthy dairy cows. Fourteen lactating Holstein cows (parity $2.6 \pm 0.3 ; 117 \pm 18 \mathrm{~d}$ in milk) were enrolled in 2 experimental periods. Period 1 ( $5 \mathrm{~d}$ ) served as the baseline for period $2(7 \mathrm{~d})$, during which cows received 1 of 2 i.v. treatments twice per day: sterile saline or a gamma-secretase inhibitor (GSI; $1.5 \mathrm{mg} / \mathrm{kg}$ of body weight). Gamma-secretase inhibitors reduce intestinal barrier function by inhibiting crypt cell differentiation into absorptive enterocytes. During period 2, control cows receiving sterile saline were pair-fed $(\mathrm{PF})$ to the GSI-treated cows, and all cows were killed at the end of period 2. Administering GSI increased goblet cell area 218, 70, and $28 \%$ in jejunum, ileum, and colon, respectively. In the jejunum, GSI-treated cows had increased crypt depth and reduced villus height, villus height-to-crypt depth ratio, cell proliferation, and mucosal surface area. Plasma lipopolysaccharide binding protein increased with time, and tended to be increased $42 \%$ in GSI-treated cows relative to PF controls on d 5 to 7. Circulating haptoglobin and serum amyloid A concentrations increased (585- and 4.4-fold, respectively) similarly in both treatments. Administering GSI progressively reduced dry matter intake $(66 \%)$ and, by design, the pattern and magnitude of decreased nutrient intake was similar in PF controls. A similar progressive decrease $(42 \%)$ in milk yield occurred in both treatments, but we observed no treatment effects on milk components. Cows treated with GSI tended to have increased plasma insulin (68\%) and decreased circulating nonesterified fatty acids (29\%) compared with $\mathrm{PF}$ cows. For both treatments, plasma glucose decreased

Received November 23, 2016.

Accepted January 30, 2017.

${ }^{1}$ Corresponding author: baumgard@iastate.edu with time while $\beta$-hydroxybutyrate progressively increased. Liver triglycerides increased $221 \%$ from period 1 to sacrifice in both treatments. No differences were detected in liver weight, liver moisture, or body weight change. Intentionally compromising intestinal barrier function caused inflammation, altered metabolism, and markedly reduced feed intake and milk yield. Further, we demonstrated that progressive feed reduction appeared to cause leaky gut and inflammation.

Key words: inflammation, insulin, intestinal integrity, lipopolysaccharide

\section{INTRODUCTION}

Appreciation is growing for the importance of proper intestinal barrier function in domestic farm animals. The luminal content of the gastrointestinal tract technically remains extrinsic to the animal, and thus serves the dual role of absorbing valuable nutrients while preventing infiltration of unwanted compounds and molecules (Mani et al., 2012). The human gastrointestinal tract has a surface area of $\sim 400 \mathrm{~m}^{2}$, which is 200 times greater than that of the skin (Murphy, 2012), and it is continuously subjected to potentially pathogenic microorganisms and toxins (Mani et al., 2012). Barrier importance is heightened in cattle, because both the size of the gastrointestinal tract and potential toxin exposure are more extensive in ruminants due to pregastric fermentation compartments. It is not surprising that a large majority of the immune system resides in the splanchnic bed (van der Heijden et al., 1987).

A variety of diseases, albeit with etiological differences, have a common dominant pathology of impaired intestinal barrier function (i.e., leaky gut), including Crohn's disease, inflammatory bowel syndrome, celiac disease, and alcoholism (Draper et al., 1983; Bargiggia et al., 2003; Ludvigsson et al., 2007; McGowan et al., 2012). Recognized circumstances in animal agriculture in which gastrointestinal tract barrier function is compromised include weaning (Boudry et al., 2004; Moeser 
et al., 2007), heat stress (Baumgard and Rhoads, 2013; Pearce et al., 2013), and rumen acidosis (Emmanuel et al., 2007; Khafipour et al., 2009; Minuti et al., 2014). Additionally, reduced feed intake decreases barrier integrity in humans (Welsh et al., 1998) and farm animals (Pearce et al., 2013; Zhang et al., 2013; Stoakes et al., 2015a). Further, we have preliminary evidence strongly implicating leaky gut as the etiological origin of ketosis in transitioning dairy cows (Abuajamieh et al., 2016). Accordingly, multiple situations experienced by farm animals have the potential to induce leaky gut.

Presumably, an impaired intestinal barrier will negatively affect economically important phenotypes. However, directly studying post-absorptive and production consequences of leaky gut is difficult, because the conditions thought to be responsible for reducing intestinal barrier integrity also affect multiple tissues and systems. Obvious examples of biologically confounding situations include the periparturient period and heat stress, both of which are accompanied by marked homeorhetic adaptations to support a new dominant physiological state (Bauman and Currie, 1980; Baumgard and Rhoads, 2013). Evaluating the metabolic, endocrine, inflammatory, and production consequences of leaky gut in isolation would provide insight into its direct impact on the pathophysiology of common onfarm disorders.

We hypothesized that intestinal tract barrier dysfunction (in apparently otherwise healthy animals) would detrimentally affect production parameters, metabolic variables, and inflammatory indices, and that these post-absorptive consequences would resemble characteristic biomarkers in the aforementioned disorders. To test this, we used gamma-secretase inhibitor (GSI) to decrease intestinal barrier integrity. Administrating GSI causes intestinal metaplasia of mucus-secreting goblet cells from crypt cells via Notch pathway interference (Milano et al., 2004; van Es et al., 2005), which is necessary for normal absorptive enterocyte maturation and proliferation (Okamoto et al., 2009). Disrupting ordinary crypt cell differentiation using GSI severely damages intestinal structures (Wong et al., 2004) and inhibiting the Notch pathway decreases epithelial cell turnover and increases intestinal permeability (Obata et al., 2012).

\section{MATERIALS AND METHODS}

\section{Animals and Sampling}

The Institutional Animal Care and Use Committee at Iowa State University approved all procedures involving animals. Fourteen lactating Holstein cows $(117 \pm 18$ DIM; $666 \pm 14 \mathrm{~kg} \mathrm{BW}$; parity $2.6 \pm 0.3)$ were housed at the Iowa State University Dairy Farm and enrolled in 2 experimental periods. Period 1 (P1) lasted 4 to $5 \mathrm{~d}$ and served as the baseline (data generated for covariate analysis) for period 2 (P2). Period 2 lasted $7 \mathrm{~d}$, during which cows received 1 of 2 i.v. treatments twice daily at 0600 and $1800 \mathrm{~h}$ : control ( $1 \mathrm{~L}$ sterile saline; $\mathrm{n}=7$ ) or GSI $(1.5 \mathrm{mg} / \mathrm{kg}$ of BW semagacestat dissolved in 1 L of sterile saline; LY-450139; Eli Lilly and Company, Indianapolis, IN; $\mathrm{n}=7$ ). The GSI dose was selected from a preliminary dose-response trial, where $1 \mathrm{mg} /$ $\mathrm{kg} / \mathrm{d}$ BW did not induce overt phenotypic responses and $6 \mathrm{mg} / \mathrm{kg}$ day caused a severe and rapid decrease in feed intake (data not shown). Control animals were pair-fed (PF) to the GSI-treated cows to eliminate the confounding effects of dissimilar nutrient intake, as we have described (Wheelock et al., 2010).

All cows were individually fed a TMR once daily at $0800 \mathrm{~h}$, and orts were recorded daily before feeding. The TMR was formulated by Nutrition Professionals Inc. (Neenah, WI) to meet or exceed the predicted requirements of energy, protein, minerals, and vitamins (NRC, 2001; Table 1). Reductions in daily feed intake by GSI-treated cows in P2 were determined as a percentage of their mean daily ad libitum intake during P1. Initiation of $\mathrm{P} 2$ for the PF cows occurred $1 \mathrm{~d}$ later to allow for pair-feeding calculations and implementation. For tissue-collection consistency, PF and GSI cows were euthanized after morning blood samples on the same

Table 1. Ingredients and composition of $\operatorname{diet}^{1}$

\begin{tabular}{lc}
\hline Composition & \% of $\mathrm{DM}^{2}$ \\
\hline Ingredient & \\
Corn silage & 33.6 \\
Alfalfa hay & 19.8 \\
Rolled corn & 17.1 \\
Ground corn & 13.7 \\
Whole cotton & 8.6 \\
Soy Plus & \\
High-protein soybean meal $^{4}$ & 4.2 \\
Chemical analysis & 3.0 \\
CP & \\
NDF & 15.7 \\
ADF & 31.6 \\
NE & Mcal/kg DM) \\
\hline
\end{tabular}

${ }^{1}$ Values represent an average of samples collected and composited throughout the trial. Dry matter averaged $53 \%$.

${ }^{2}$ Average nutrient levels: $5.74 \%$ fat, $0.84 \% \mathrm{Ca}, 0.34 \% \mathrm{P}, 0.37 \% \mathrm{Mg}$, $0.19 \% \mathrm{~S}, 1.1 \% \mathrm{~K}, 0.44 \% \mathrm{Na}, 0.47 \% \mathrm{Cl}, 56.30 \mathrm{mg} / \mathrm{kg} \mathrm{Zn}, 60.08 \mathrm{mg} / \mathrm{kg}$ $\mathrm{Mn}, 95.76 \mathrm{mg} / \mathrm{kg} \mathrm{Fe}, 17.28 \mathrm{mg} / \mathrm{kg} \mathrm{Cu}, 0.19 \mathrm{mg} / \mathrm{kg} \mathrm{Co}, 0.28 \mathrm{mg} / \mathrm{kg} \mathrm{Se}$, $43.68 \mathrm{mg} / \mathrm{kg} \mathrm{I}, 4,475.9 \mathrm{IU} / \mathrm{kg}$ vitamin A, 1,438.8 IU $/ \mathrm{kg}$ vitamin $\mathrm{D}$, and $26.95 \mathrm{IU} / \mathrm{kg}$ vitamin $\mathrm{E}$.

${ }^{3}$ Cooker-expeller processed soybean meal produced by West Central Cooperative (Ralston, IA), containing $46.6 \%$ CP, 60\% RUP (\% CP); DM basis.

${ }^{4}$ Solvent-extracted soybean meal containing $54.5 \%$ CP, 35\% RUP (\% $\mathrm{CP})$; DM basis. 
calendar day (P2 d 8 for GSI-treated cows and P2 d 7 for $\mathrm{PF}$ cows).

Throughout the experiment, cows were milked twice daily at 0500 and $1700 \mathrm{~h}$, and yields were recorded at each milking. Individual milk samples were obtained daily for composition analysis during both periods at the morning milking. Samples were stored at $4^{\circ} \mathrm{C}$ with a preservative (bronopol tablet; D\&F Control System, San Ramon, CA) until analysis by Dairy Lab Services (Dubuque, IA) using AOAC International-approved infrared analysis equipment and procedures (AOAC International, 1995; method 972-16).

Heart rate, respiration rate, rectal temperature, and manure score were measured twice daily at 0700 and $1900 \mathrm{~h}$. Heart rate and respiration rate were measured as beats or flank movements during a $15 \mathrm{~s}$ interval and later transformed to beats/min and breaths/min, respectively. Rectal temperatures were measured using a digital thermometer (M700; GLA, San Luis Obispo, $\mathrm{CA}$ ). The manure score for each animal was determined based on a scale of 1 (liquid) to 5 (firm) using the scoring system of Skidmore et al. (1996). Body weights were recorded on d 5 of P1 to calculate GSI dosage and again immediately preceding death.

A jugular catheter was inserted into each cow as previously described (Baumgard et al., 2002) before P1 for blood sampling, and a second catheter was inserted $1 \mathrm{~d}$ before P2 for GSI or saline administration. Serum and plasma samples were collected daily at $0500 \mathrm{~h}$ during both periods using an empty glass tube and a glass tube containing $50 \mu \mathrm{L}$ of sterile heparin (Sagent Pharmaceuticals, Schaumburg, IL), respectively. Pyrogen-free serum samples were collected on $\mathrm{d} 3$ and 5 of $\mathrm{P} 1$ and on $\mathrm{d} 1,3,5$, and 7 of P2. Before collection, the coccygeal area was scrubbed with alcohol-soaked gauze, and the sample was collected via venipuncture into evacuated sterile serum collection tubes (Vacutainer; BD, Franklin Lakes, NJ) and handled in sterile conditions from then on. Serum samples were allowed to clot for 1 hour at room temperature. Plasma and serum were harvested following centrifugation at $1,500 \times g$ for 15 min at $4^{\circ} \mathrm{C}$, and then frozen at $-20^{\circ} \mathrm{C}$ until analysis.

\section{Tissue Collection}

Liver biopsies were collected on d 3 of P1 and d 5 of P2, as previously described (Rhoads et al., 2009). Briefly, the area was shaved, disinfected, and locally anesthetized using lidocaine before performing a percutaneous biopsy with a trocar. Four samples $(\sim 20 \mathrm{mg}$ each) were collected, snap-frozen in liquid nitrogen, and stored at $-80^{\circ} \mathrm{C}$ until analyzed. Incisions were then sutured and topically treated with AluShield (Neogen Corp., Lexington, KY).
Cows were euthanized with a CASH Special captive bolt gun (Accles \& Shelvoke Ltd., Sutton Coldfield, UK) using a large animal charge, followed by exsanguination, which was completed by severing the carotid arteries bilaterally. Liver and intestinal tissues were harvested immediately, and liver and spleen weights were recorded. A liver sample was collected from $\sim 20$ $\mathrm{cm}$ dorsal to the ventral liver margin (a location anticipated to be where the liver biopsies were obtained) and was snap-frozen in liquid nitrogen and stored at $-80^{\circ} \mathrm{C}$ until further analysis. A jejunum segment was collected $\sim 5.5 \mathrm{~m}$ proximal to the ileocecal junction. An ileum segment was collected immediately proximal to the ileocecal junction. A colon segment was collected $\sim 1.5 \mathrm{~m}$ proximal to the pelvic inlet. Jejunum, ileum, and colon segments $(\sim 20$ to $30 \mathrm{~cm})$ were flushed with cold PBS to remove intestinal contents. A transversal section was collected from each sample and fixed in 10\% neutral buffered formalin for later histological analysis.

\section{Blood Analyses}

Plasma insulin, nonesterified fatty acids (NEFA), glucose, BHB, LPS-binding protein (LBP), serum amyloid A (SAA), haptoglobin, and BUN concentrations were determined using commercially available kits validated for use in our laboratory (insulin, Mercodia AB, Uppsala, Sweden; NEFA, Wako Chemicals USA Inc., Richmond, VA; glucose, Wako Chemicals USA Inc.; BHB, Pointe Scientific Inc., Canton, MI; LBP, Hycult Biotech, Uden, the Netherlands; SAA, Tridelta Development Ltd., Kildare, Ireland; haptoglobin, Immunology Consultants Laboratory Inc., Portland, OR; BUN, Teco Diagnostics Anaheim, CA). The inter- and intra-assay coefficients of variation for insulin, NEFA, glucose, BHB, LBP, SAA, and BUN assays were 6.7 and $17.5 \%, 7.1$ and $7.3 \%, 6.9$ and $5.9 \%, 27.3$ and $5.3 \%$, 14.3 and $4.6 \%$, and 5.8 and $1.9 \%$, respectively. Serum LPS was analyzed in triplicate using sterile procedures and a PyroGene endotoxin detection assay (Lonza, Walkersville, MD); inter- and intraassay coefficients of variation were 64.9 and $29.7 \%$, respectively.

\section{Liver Analyses}

Portions of the liver samples $(\sim 5.0 \mathrm{~g})$ were weighed, dried in an oven for $18 \mathrm{~h}$ at $102^{\circ} \mathrm{C}$, and reweighed after cooling to determine liver moisture percentage. To determine liver triglyceride content, a portion $(\sim 20$ $\mathrm{mg}$ ) was weighed and homogenized with $500 \mu \mathrm{L}$ chilled PBS. The homogenate was then centrifuged at $8,000 \times$ $g$ for $2 \mathrm{~min}$ at $4^{\circ} \mathrm{C}$. Free glycerol was immediately determined using $10 \mu \mathrm{L}$ of supernatant and the enzymatic glycerol phosphate oxidase method (Sigma-Aldrich, St. 
Louis, MO). An additional $300 \mu \mathrm{L}$ of supernatant was removed and incubated with $75 \mu \mathrm{L}$ of lipase (MP Biomedicals, Solon, $\mathrm{OH}$ ) at $37^{\circ} \mathrm{C}$ for $16 \mathrm{~h}$ before determining total glycerol using the same enzymatic glycerol phosphate oxidase method. Free glycerol (before lipase digestion) was subtracted from total glycerol (after lipase digestion) to determine triglyceride content, and this was expressed as a percentage of the wet weight of the original sample before homogenization. The intraassay coefficients of variation for free glycerol and total glycerol were 1.9 and $0.8 \%$, respectively.

\section{Histological Analyses}

For histological analysis, $10 \%$ neutral buffered formalin-fixed jejunum, ileum, and colon were sectioned and periodic acid-Schiff (PAS) stained at the Iowa State University Veterinary Diagnostic Laboratory for morphological and goblet cell area quantification. One slide per cow per tissue was generated. For histological and goblet cell analysis, a microscope (DMI3000 B Inverted Microscope; Leica, Bannockburn, IL) with an attached camera (12-bit QICAM Fast 1394; QImaging, Surrey, BC) was used to obtain images from 5 non-overlapping fields per slide at $100 \times$ magnification. All morphological measurements were obtained using ImageJ (1.48b, National Institutes of Health, Bethesda, $\mathrm{MD})$. For villus measurements, 1 villus per image was measured, for a total of 5 measurements per cow. Total mucosal area was determined after subtracting luminal area, and the area of the PAS stain was measured using the ImageJ color deconvolution tool with H PAS vector. Goblet cell area was expressed as the percentage of the total mucosal area stained by PAS. Villus height was measured from the villus tip to the villus-crypt interface. Villus $(v$.) width was measured at mid-villus height. Crypt depth was measured from the villus-crypt opening to the laminae propria. Crypt (c.) width was measured at the villus-crypt interface level. A mucosal surface area estimate was obtained using the mucosalto-serosal amplification ratio $\mathrm{M}$, as previously reported by Kisielinski et al. (2002), where

$$
\mathrm{M}=\frac{(v \cdot \text { width } \times \text { v. length })+\left(\frac{v \cdot \text { width }}{2}+\frac{\text { c. width }}{2}\right)^{2}-\left(\frac{v \cdot \text { width }}{2}\right)^{2}}{\left(\frac{v \cdot \text { width }}{2}+\frac{c \cdot \text { width }}{2}\right)^{2}} .
$$

\section{Immunofluorescence Staining}

For immunofluorescence analysis, $10 \%$ neutral buffered formalin-fixed jejunum, ileum, and colon were sectioned at a thickness of $5 \mu \mathrm{m}$ and mounted in the histol- ogy laboratory at the Iowa State University Veterinary Diagnostic Laboratory. Slides were deparaffinized using Citrisolv Hybrid Solvent (Fisher Scientific, Pittsburgh, PA), rehydrated by incubation for 3 min twice in $100 \%$ ethanol, 95\% ethanol for $1 \mathrm{~min}, 80 \%$ ethanol for $1 \mathrm{~min}$, and then rinsed in distilled and deionized water. Antigen retrieval was performed by incubating slides in citrate buffer (sodium citrate, citric acid, Tween20, water) at $95^{\circ} \mathrm{C}$ for $30 \mathrm{~min}$. Tissue sections were blocked in 5\% BSA (Sigma-Aldrich) in PBS for 90 to 180 min. Primary antibody against proliferating cell nuclear antigen (PC10 monoclonal antibody, Cell Signaling Technology \#2586; 1:200 dilution), a marker of cellular proliferation, was applied to each section and incubated overnight at $4^{\circ} \mathrm{C}$. Slides were washed 3 times in PBS and incubated in fluorescent secondary antibody [anti-mouse $\operatorname{IgG}\left(\mathrm{H}^{+} \mathrm{L}\right) \mathrm{F}(\mathrm{ab})_{2}$ fragment, AlexaFluor 488 conjugate, Cell Signaling Technology 4408; 1:1,000 dilution] for 1 $\mathrm{h}$ at room temperature. Slides were washed 3 times in PBS, and 4',6-diamidino-2-phenylindole (DAPI) stain was applied to each section. Slides were stored in the dark at $4^{\circ} \mathrm{C}$ to prevent fading. To decrease variability due to staining day, each tissue type was stained on the same day, and slides were imaged within $6 \mathrm{~h}$. For each animal, 5 images from each tissue were collected on a Leica fluorescent microscope at $100 \times$ magnification. To ensure antibody binding specificity, negative controls omitted the primary antibody, the secondary antibody, or both. Mouse IgG was used in place of the primary antibody to control for antibody isotype nonspecific binding. Fluorescence signaling was obtained for 1 individual villus per image in the jejunum and ileum samples, and the total fluorescence of each colon image was performed using integrated density quantification in ImageJ.

\section{Statistical Analyses}

For production and blood parameters, the effects of treatment, day, and treatment $\times$ day interaction were assessed using PROC MIXED (SAS Institute, Inc., Cary, NC) and a repeated measures analysis with an autoregressive covariance structure and day as the repeated effect. The P1 value for each specific variable (when available) served as a covariate. For postmortem data, the effect of treatment was also assessed using PROC MIXED. Immunofluorescence staining data were analyzed using the unpaired $t$-test function in GraphPad Prism (GraphPad Software Inc., La Jolla, CA). Irrespective of treatment, Pearson correlation analysis between intestinal parameters and the change in circulating inflammatory parameters ( $\mathrm{P} 2 \mathrm{~d} 5-7$ average minus P1 average) was conducted using PROC CORR in SAS. Data are reported as least squares means and 
were considered significant if $P \leq 0.05$; a tendency was declared if $0.05<P \leq 0.15$.

\section{RESULTS}

During P2, GSI administration progressively decreased DMI $(P<0.01$; Figure 1A), and feed intake was reduced $66 \%$ by the end of the study. By experimental design, the pattern and extent of feed intake reduction was similar in $\mathrm{PF}$ cows $(P=0.96$; Figure $1 \mathrm{~A})$. There was a similar and progressive decline in milk yield for both treatments during P2 $(P<0.01$; Figure 1B), whereby milk yield was reduced $42 \%$ by the end of the study. There were no differences in milk components between treatments, but we did observe a tendency for milk SCC and MUN to be increased in GSI-treated cows (144 and 22\%, respectively, $P \leq 0.08$; Table 2). Milk fat content increased (45\%) over time for both PF and GSI treatments $(P=0.05$; Table 2).

Manure score was decreased $29 \%$ in GSI-treated cows $(P=0.03$; Figure $1 \mathrm{C})$ due to a progressive reduction that did not occur in PF controls. Overall, GSI-treated cows had slightly increased heart rate and respiration rate compared to $\mathrm{PF}$ cows ( 8 beats/min and 7 breaths/ min, respectively; $P \leq 0.01$; Table 2 ). There was a tendency for GSI-treated cows to have an increased rectal temperature compared to $\mathrm{PF}$ controls $\left(38.6\right.$ vs. $38.4^{\circ} \mathrm{C}$; $P=0.06$; Table 2).

Plasma glucose concentrations decreased slightly with time $(P=0.05$; Figure $2 \mathrm{~A})$ in both treatments. Cows treated with GSI tended to have increased plasma insulin (68\%) and decreased circulating NEFA (29\%) compared with $\mathrm{PF}$ controls $(P \leq 0.07$; Figures $2 \mathrm{~B}$ and 2C). Circulating NEFA increased with time in both treatments $(P<0.01$; Figure $2 \mathrm{C})$, whereby at the end of P2, NEFA were increased 5.2- and 2.2-fold relative to baseline values in PF and GSI-treated cows, respectively. There was a tendency for a treatment $\times$ day interaction in plasma BHB due to a more pronounced increase in GSI-treated cows (124\% increase on d 7 from baseline; Figure 2D) compared with PF controls $(81 \%$ increase on d 6 from baseline) over time. We detected no differences in circulating BUN (data not shown). Cows treated with GSI tended to have a $70 \%$ decrease in circulating LPS on $\mathrm{d} 5$ and 7 relative to PF cows $(P$ $=0.12$; Figure $3 \mathrm{~A})$. Plasma LBP increased with time $(P<0.01$; Figure 3B) and tended to be increased $42 \%$ in GSI-treated cows compared with PF controls on d 5 to $7(P=0.14$; Figure 3B). Haptoglobin and SAA progressively increased similarly in both treatments, and were 585- and 4.4-fold higher, respectively, at the end of $\mathrm{P} 2$ relative to baseline $(P<0.01$; Figure $3 \mathrm{C}$ and $3 \mathrm{D})$.

Compared with PF controls, administering GSI increased goblet cell area 218, 70 , and $28 \%$ in jejunum, ileum, and colon, respectively $(P \leq 0.02$; Figure $4 \mathrm{~A}$ and Figure 5). Jejunum villus height, villus height-to-crypt depth ratio, and mucosal surface area were reduced (21, 36, and 21\%, respectively) in GSI-treated cows, and jejunum crypt depth was increased $43 \%$ compared with PF controls $(P<0.01$; Figures $4 \mathrm{~B}, 4 \mathrm{D}$, and $4 \mathrm{E})$. Jejunum villus width was not affected by treatment. Crypt depth tended to be increased $21 \%$ in the ileum of GSI-treated animals relative to controls $(P=0.06$; Figure $4 \mathrm{C}$ ), but there were no other detectable effects on ileum morphology. Intestinal cellular proliferation, as measured by proliferating cell nuclear antigen (PCNA), was decreased $27 \%$ in the jejunum of GSI-treated cows relative to $\mathrm{PF}$ controls $(P<0.01)$, but no differences were observed in the ileum or colon (Figure $4 \mathrm{~F}$ and Figure 6).

Irrespective of treatment, the change in circulating LBP (P2 d 5 to 7 average minus P1 average) was correlated with the jejunum villus height-to-crypt-depth ratio $(\mathrm{r}=-0.89, P<0.01$; Figure 7 ), as well as jejunum crypt depth and villus height $(\mathrm{r}=0.84$ and -0.69 , respectively, $P \leq 0.01$; data not shown). Change in circulating SAA was correlated with jejunum villus width $(\mathrm{r}=0.64, P=0.03)$ and tended to be correlated with the villus height-to-crypt depth ratio and mucosal surface area $(\mathrm{r}=-0.47$ and -0.53 , respectively, $P \leq$ 0.13 ; data not shown). Circulating haptoglobin change tended to be correlated with jejunum villus width and jejunum mucosal surface area $(\mathrm{r}=0.50$ and $-0.44, P$ $\leq 0.15$; data not shown). In the ileum, there were no correlations between changes in acute phase proteins and intestinal morphology parameters.

Liver triglyceride content was increased $221 \%$ at death relative to baseline in both treatments $(P<0.01$; Figure 8$)$. There were no treatment differences in liver weight, liver moisture percentage, liver or spleen weight as a percentage of $\mathrm{BW}$, or change in overall BW (Table $3)$.

\section{DISCUSSION}

A variety of situations in animal agriculture can reduce intestinal barrier function, the consequences of which likely stimulate the immune system, cause inflammation, and eventually compromise production. Examples include weaning (Boudry et al., 2004; Moeser et al., 2007), heat stress (Baumgard and Rhoads, 2013; Pearce et al., 2013), rumen acidosis (Emmanuel et al., 2007; Khafipour et al., 2009; Minuti et al., 2014), and the periparturient period (Abuajamieh et al., 2016). However, a myriad of behavioral, metabolic, and endocrine events accompanying these situations make it difficult to study the consequences of poor intestinal barrier health in isolation. To our knowledge, a controlled 

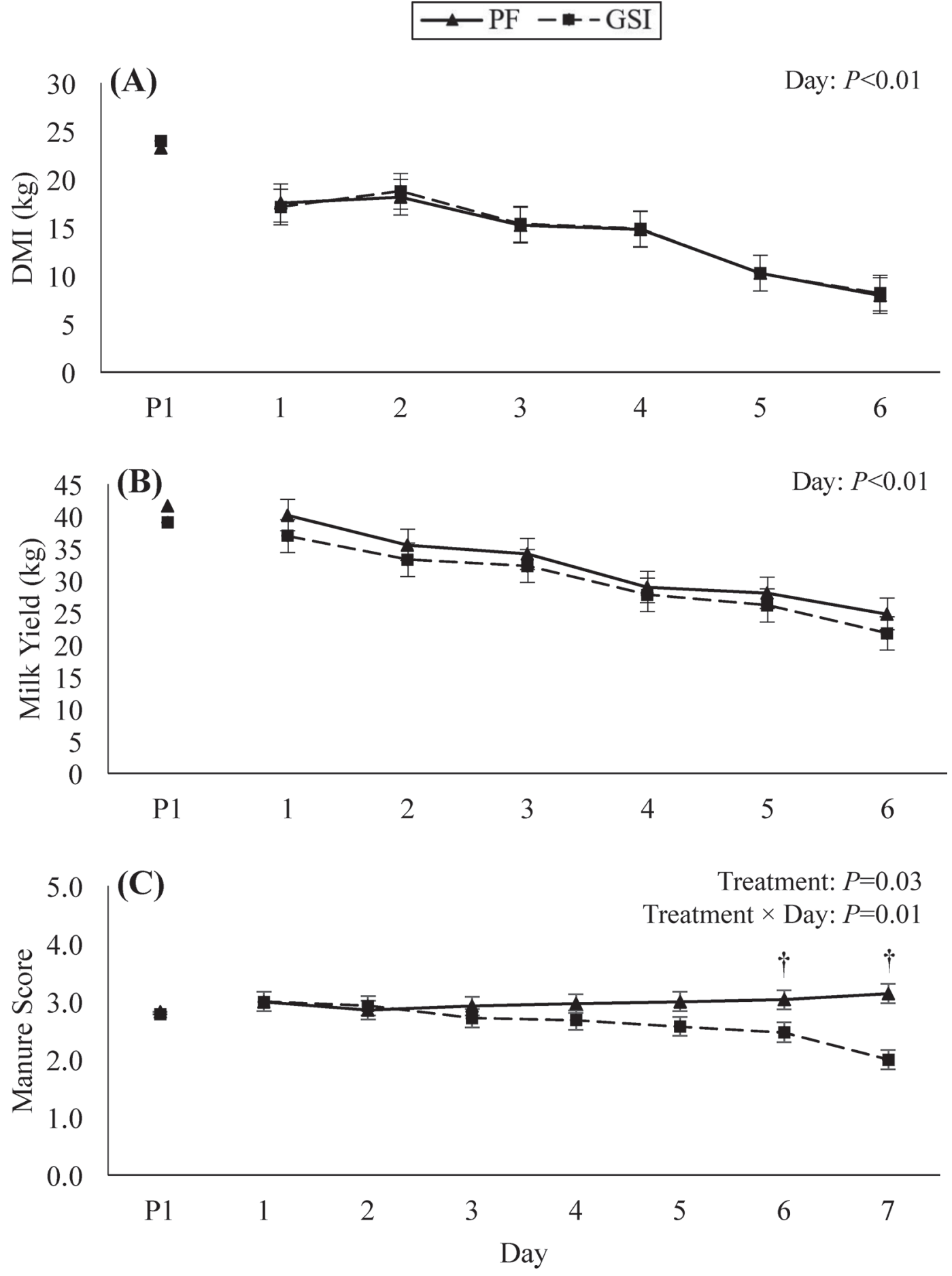

Figure 1. Effects of gamma-secretase inhibitor (GSI) or pair-feeding (PF) on (A) DMI; (B) milk yield; and (C) manure score in lactating Holstein cows. Values for P1 represent the period 1 average that was statistically used as a covariate. Results are expressed as LSM \pm SEM. $\dagger$ Indicates a significant treatment effect $(P \leq 0.05)$.

experiment intentionally reducing intestinal barrier integrity has never been performed in ruminants. Our objectives were to elucidate the inflammatory, production, and metabolic consequences of intestinal barrier dysfunction in otherwise healthy mid-lactation dairy cows.

Administering GSI in our experiment disturbed intestinal architecture, changes likely reflective of leaky gut 
Table 2. Effects of gamma-secretase inhibitor (GSI) or pair-feeding (PF) on production variables and vital measurements

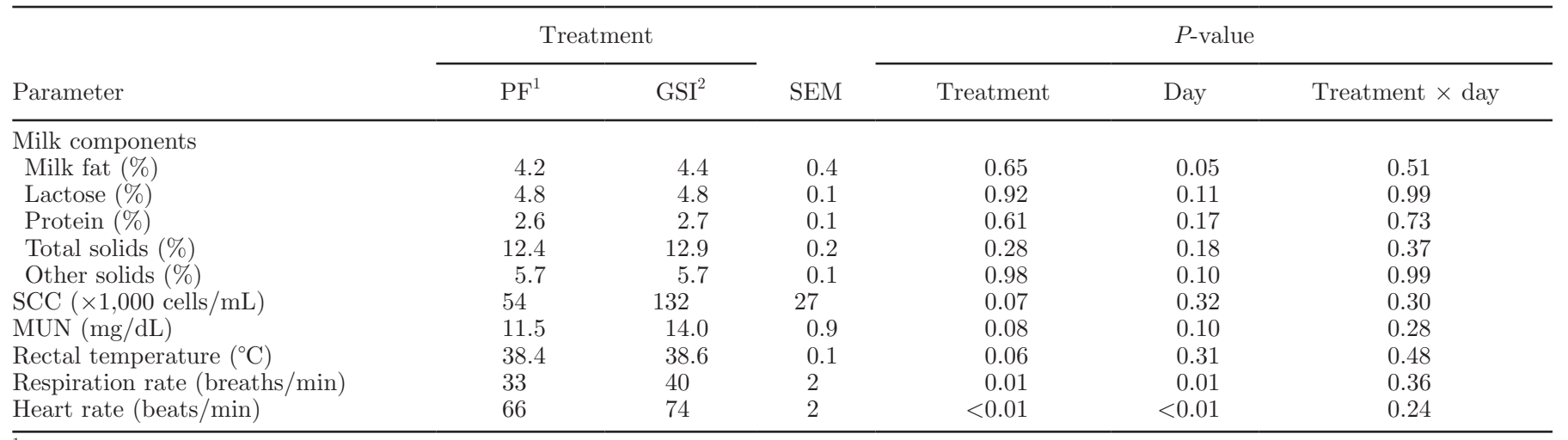

${ }^{1}$ Cows pair-fed to gamma-secretase inhibitor treatment and administered $1 \mathrm{~L}$ of saline twice daily.

${ }^{2}$ Cows administered $1.5 \mathrm{mg} / \mathrm{kg}$ of BW gamma-secretase inhibitor twice daily.

(Ford et al., 1985; Pearce et al., 2013). Crypt cell Notch signaling is inhibited by GSI (De Strooper et al., 1999), and altering this pathway increases intestinal permeability (Obata et al., 2012). Furthermore, GSI decreases absorptive enterocyte proliferation and causes goblet cell hyperplasia (van Es et al., 2005), which was evident in the current study because of the decrease in jejunal cell proliferation and the increase in goblet cell area in jejunum, ileum, and colon. The effects of GSI were particularly evident in the jejunum, because changes in villus height, crypt depth, their ratio, and mucosal surface area are indicative of damaged epithelium (van der Hulst et al., 1998; Pearce et al., 2013). We do not know why the jejunum was more sensitive to GSI than the ileum and colon, but a plausible explanation is a larger proportion of absorptive enterocytes in jejunum villi relative to other segments of the gastrointestinal tract (Cheng and Leblond, 1974). Additionally, goblet cell hyperplasia likely contributed to the progressive decrease in manure scores (indicative of increased fecal moisture) due to increased mucus production.

The direct consequence of intestinal barrier dysfunction is the increased leakage of luminal antigens into the bloodstream, with the potential to initiate an inflammatory response. Elevated rectal temperature, heart rate, and respiration rate are indicative of immunoactivation (Jacobsen et al., 2005), and these were increased in cows administered GSI, suggesting a greater degree of inflammation. To further assess inflammation, we measured 3 acute phase proteins: haptoglobin, SAA, and LBP. The liver produces acute phase proteins as a secondary (non-local) response to toxic stimuli, and they have been widely acknowledged as markers of systemic inflammation (Ceciliani et al., 2012). Admittedly, acute phase protein production is a nonspecific response to endotoxin infiltration that could originate from a wide variety of sources (e.g., uterus, mammary). However, in the present study, because of the localized intestinal effects of GSI and lack of overt extra-intestinal infection, intestinal barrier dysfunction was the ostensible source of the acute phase protein response. Levels of all 3 measured acute phase proteins increased from P1 to P2 in both GSI and PF cows. The increased circulating acute phase proteins in PF cows was not unexpected, because reduced nutrient intake has been reported to compromise intestinal integrity in rodent, pig, and human models (Rodriguez et al., 1996; Welsh et al., 1998; Pearce et al., 2013), and we have demonstrated that reduced feed intake negatively affects ileum morphology in lactating cows (Stoakes et al., 2015a). After $5 \mathrm{~d}$ of treatment, LBP levels tended to be increased in GSI-treated cows compared with PF controls (Figure 3B). Interestingly, the magnitude of increased circulating LBP in GSI-infused cows mirrored the increase observed in cows with ketosis and rumen acidosis (Khafipour et al., 2009; Abuajamieh et al., 2016), indicating a similar inflammatory response to seemingly differing and unconnected disorders. Incidentally, this was also the period (near the end of P2) when treatment differences in LPS were largest (Figure 3A). Binding of LBP to LPS is essential for the activation of its receptor TLR-4 and the subsequent production of inflammatory mediators (Lu et al., 2008). Therefore, LPS clearance partially depends on LBP, and interpreting changes in both can be difficult when considering them independently. Changes in circulating LBP were well correlated with jejunal intestinal morphology parameters of villus height, crypt depth, and the villus height-to-crypt depth ratio, suggesting that changes in circulating LBP are responsive to the degree of intestinal damage and decreased barrier function (i.e., $\sim 79 \%$ of the variation in circulating LBP changes can be explained by the jejunum villus height-to-crypt depth ratio). Reasons why LBP could be a more sensi- 
$\longrightarrow$ PF - - GSI
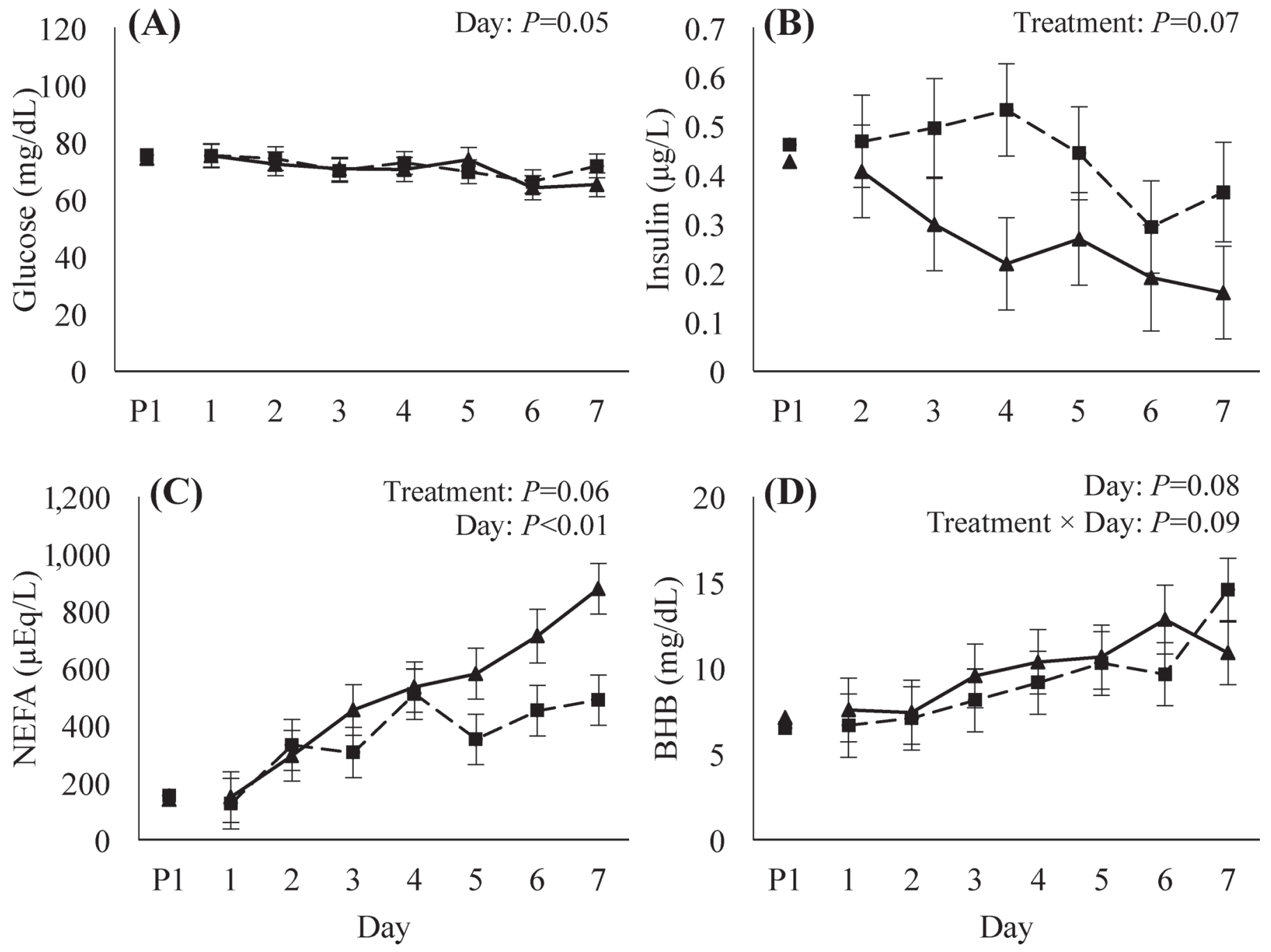

Figure 2. Effects of gamma-secretase inhibitor (GSI) or pair-feeding (PF) on plasma metabolites (A) glucose; (B) insulin; (C) nonesterified fatty acids (NEFA); and (D) BHB in lactating Holstein cows. Values for P1 represent the period 1 average that was statistically used as a covariate. Results are expressed as LSM \pm SEM.

tive marker of leaky gut-induced inflammation than the other acute phase proteins measured remains unknown, but is likely because the LBP is specific for LPS clearance, and SAA and haptoglobin play more broad roles in combating infection (Ceciliani et al., 2012). The increased LBP levels during the end of P2, coupled with the histological data, suggest GSI treatment had a more detrimental effect on intestinal integrity, resulting in increased luminal content leakage into the portal blood, and perhaps a more robust response to detoxifying LPS compared with PF cows.

Using the pair-feeding design allowed us to discriminate between the direct effects of GSI and the indirect effects of GSI-mediated reduced DMI. Hence, the GSI- treated cows had a progressive and marked decrease in DMI and, by design, the PF controls had a similar pattern and magnitude of feed intake reduction. The GSI treatment induced a steady decrease in milk yield, but this appeared to be mostly related to inadequate feed consumption, because the PF cows had a comparable decrease in both pattern and severity. For the present experiment, we assumed decreased DMI was a consequence of GSI-induced leaky gut, but we acknowledge GSI may alter appetite by an unknown extra-intestinal mechanism. Nevertheless, decreased feed intake, milk yield, or both are characteristic of inflammatory situations such as weaning, heat stress, transition period disorders, and rumen acidosis. The magnitude of decreased 
DMI and milk yield in the present study was more extensive than the majority of these circumstances, but the postabsorptive metabolism and inflammatory responses underpinning the aforementioned disorders shared similarities with what is described here.

The metabolic profile of the current model resembles conditions involving immune system activation, further evidence supporting the hypothesis that leaky gut is the cause of many on-farm disorders. For example, despite marked reductions in feed intake, plasma insulin levels remained unchanged from P1 in the GSI-treated cows, but progressively decreased as expected in the $\mathrm{PF}$ cows. By d 5 to 7 of $\mathrm{P} 2$, insulin concentrations were increased $79 \%$ in GSI-treated cows compared with PF controls. The increased insulin (a potent anabolic hor- mone) in GSI-treated cows was energetically difficult to explain, because feed intake was severely depressed and cows were obviously in an intensely catabolic condition (i.e., $>40 \mathrm{~kg}$ of BW loss). However, this unusual temporal pattern was similar to the increased insulin levels experienced by a variety of species exposed to heat stress, another leaky gut-inducing and catabolic condition (Baumgard and Rhoads, 2013). The insulin differences may be partially explained by LPS, because infusing LPS into the mammary gland increased circulating insulin in lactating cows (Waldron et al., 2006), and we have demonstrated increased circulating insulin in pigs, calves, and lactating cows infused i.v. with LPS (Rhoads et al., 2009; Stoakes et al., 2015b; Kvidera et al., 2016, 2017). The changes in insulin were not reflect-

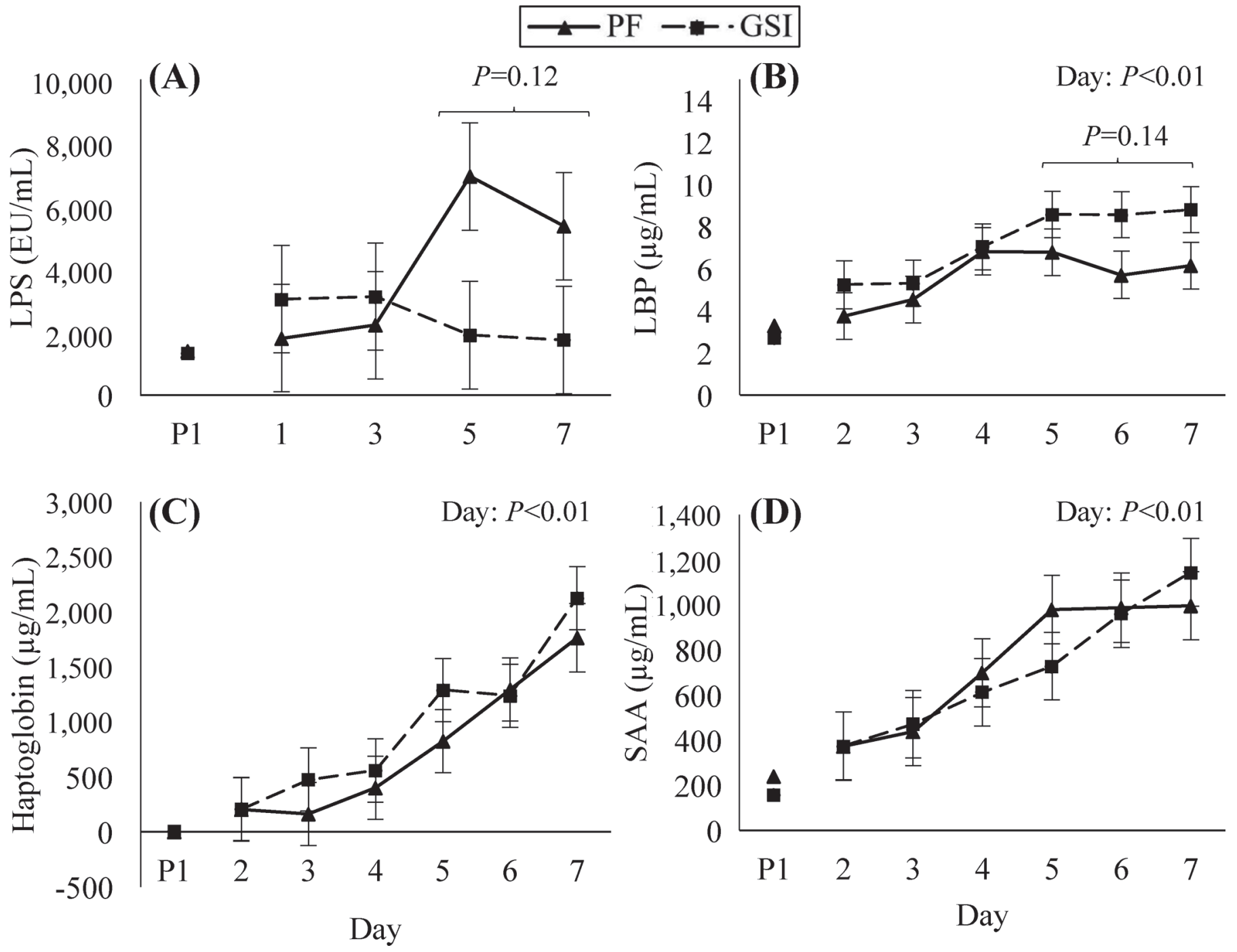

Figure 3. Effects of gamma-secretase inhibitor (GSI) or pair-feeding (PF) on blood acute phase proteins (A) LPS, (B) LPS-binding protein (LBP), (C) haptoglobin, and (D) serum amyloid A (SAA) in lactating Holstein cows. Values for P1 represent the period 1 average that was statistically used as a covariate. Results are expressed as LSM \pm SEM. 
- PF $\square$ GSI
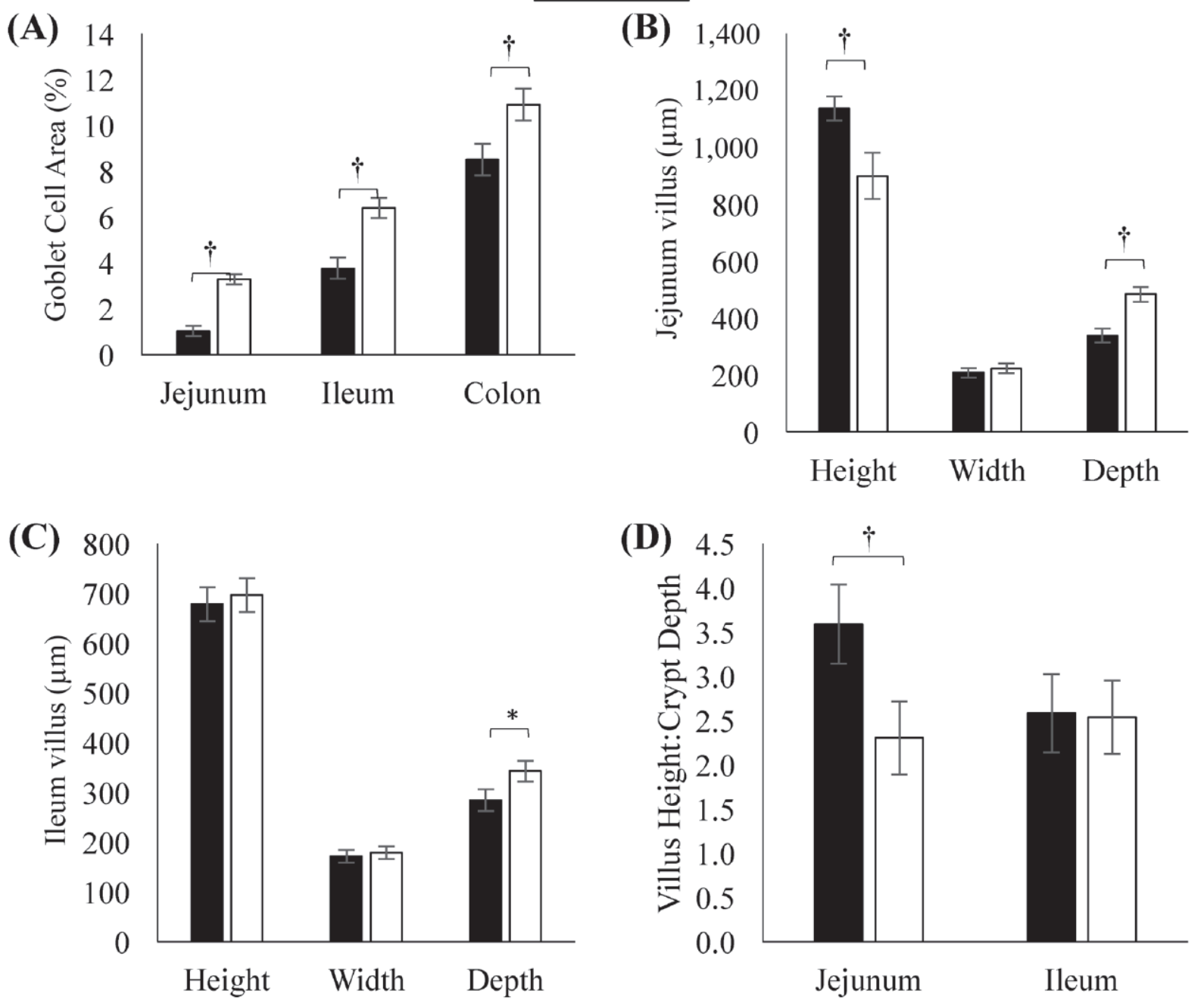

(E)
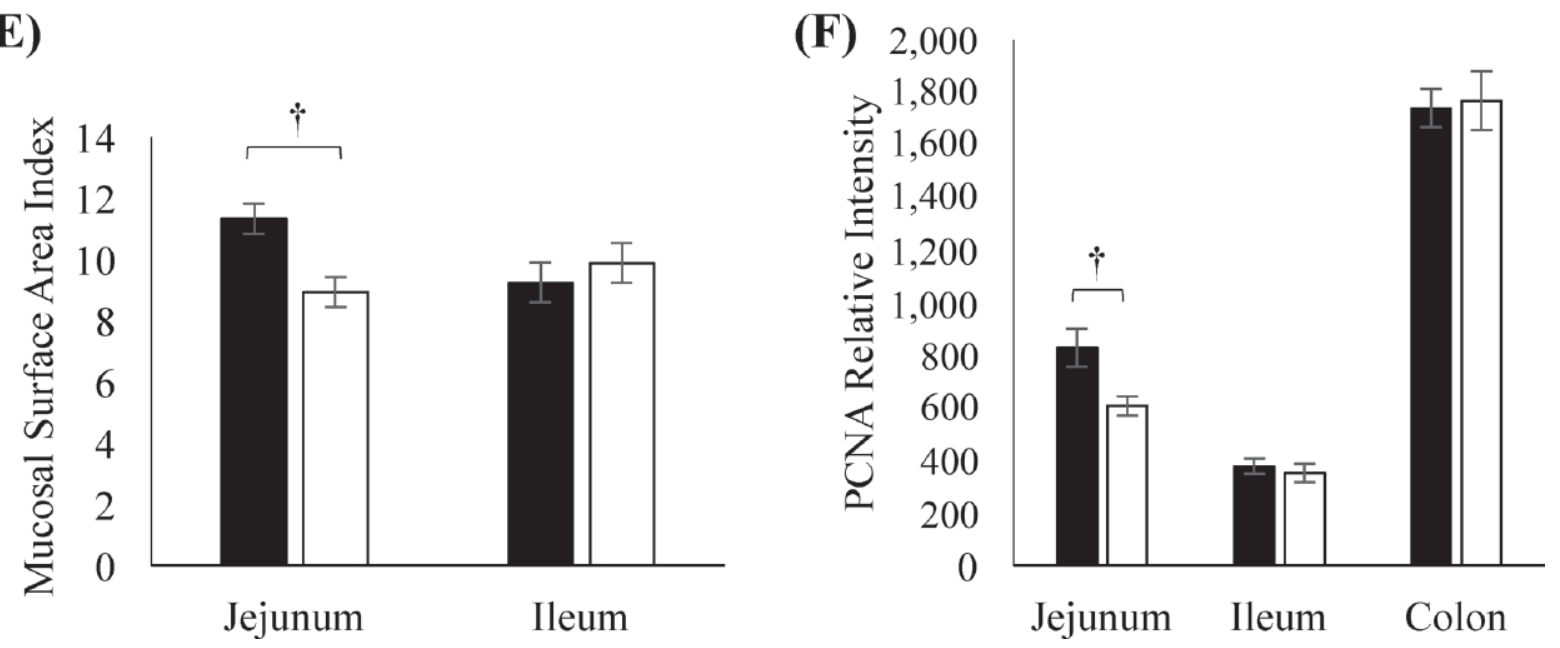

Figure 4. Effects of gamma-secretase inhibitor (GSI) or pair-feeding (PF) on (A) goblet cell area as a percentage of epithelial area in jejunum, ileum, and colon; (B) jejunum villus morphology; (C) ileum villus morphology; (D) villus height-to-crypt depth ratio in jejunum and ileum; (E) mucosal surface area in jejunum and ileum; and (F) intensity of proliferating cell nuclear antigen (PCNA) protein in jejunum, ileum, and colon. Results are expressed as LSM \pm SEM. *Indicates a tendency for a treatment effect $(P \leq 0.15)$. $\dagger$ Indicates a significant treatment effect $(P \leq 0.05)$. Mucosal surface area is expressed as an M-index as described by Kisielinski et al. (2002). 

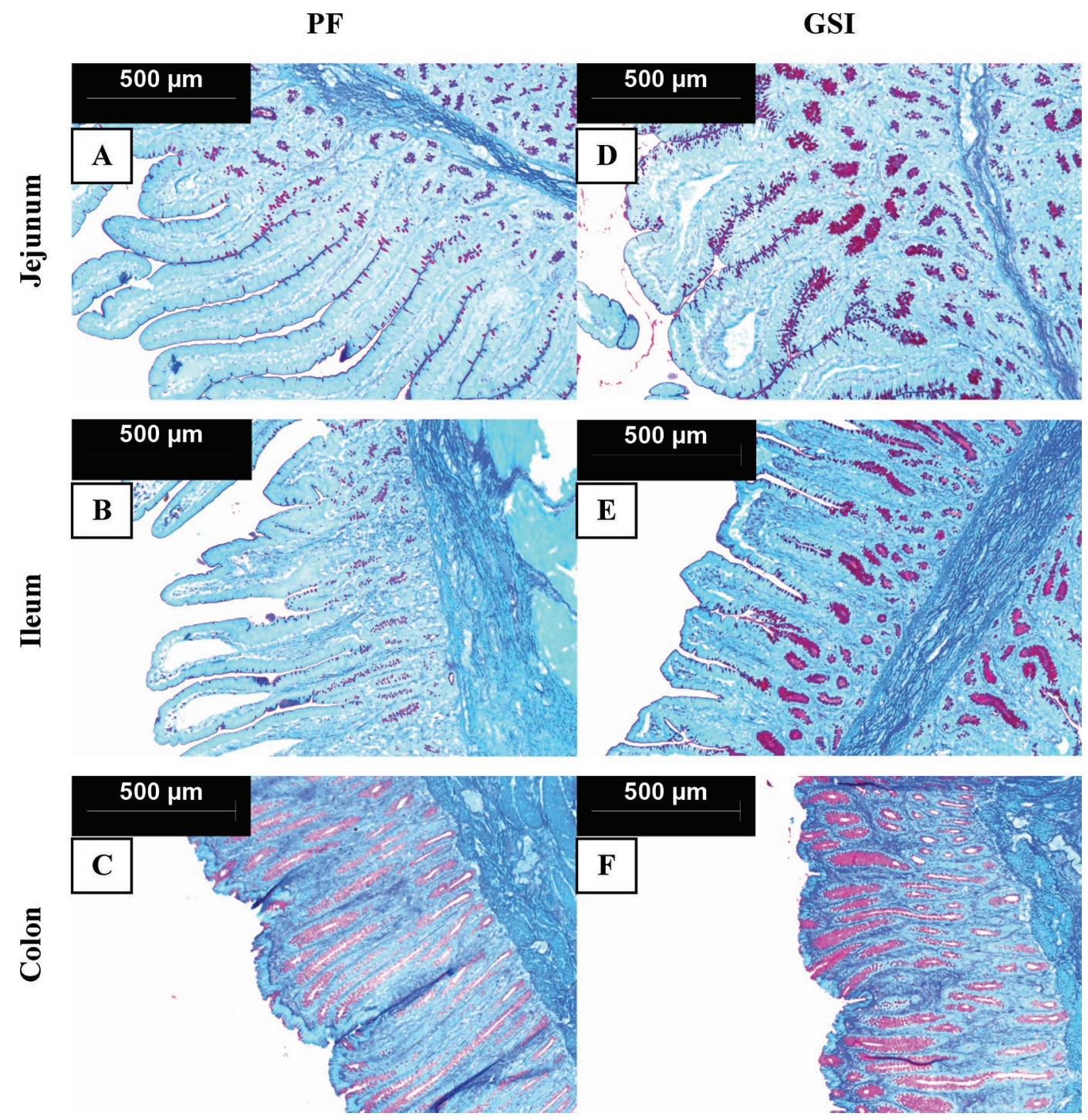

Figure 5. Representative images of periodic acid-Schiff stained (A) jejunum, (B) ileum, and (C) colon of pair-fed controls (PF), and (D) jejunum, (E) ileum, and (F) colon of cows administered gamma-secretase inhibitor (GSI). Dark purple stain is positive for mucosubstances.

ed in circulating glucose, which decreased similarly over time for both treatments, suggesting that GSI-treated cows may have become slightly insulin-resistant. This profile fits with a status of immunoactivation that is characterized by hyperinsulinemia and whole-body insulin resistance (Lang et al., 1990; McGuinness, 2005; Kvidera et al., 2016, 2017), redirecting glucose away from major disposal sites (i.e., muscle and adipose) and toward the immune system, a substantial insulininduced and insulin-independent glucose user when it is activated (Lang et al., 1990; Maratou et al., 2007; Palsson-McDermott and O'Neill, 2013). We have previously established that the intensely activated immune system of a lactating dairy cow requires over $1 \mathrm{~kg}$ of glucose in a 12-h period (Kvidera et al., 2017), and this highlights the fact that immune stimulation comes at a huge glucose cost. Thus, the aforementioned changes in carbohydrate metabolism appear to be a strategy to both "spare glucose" (muscle and adipose tissue insulin resistance) and activate/provide fuel for the immune system (hyperinsulinemia).

As expected, considering inadequate energy intake, there was a progressive and marked increase in plasma NEFA levels during P2 in both treatment groups; however, GSI cows tended to have a $41 \%$ decrease in circulating NEFA on d 5 to 7 compared with PF cows. The treatment differences in insulin likely explained the differences in circulating NEFA, because insulin is a potent antilipolytic signal (Vernon, 1992), and these insulin/ NEFA idiosyncrasies mimic the metabolic fingerprint of 

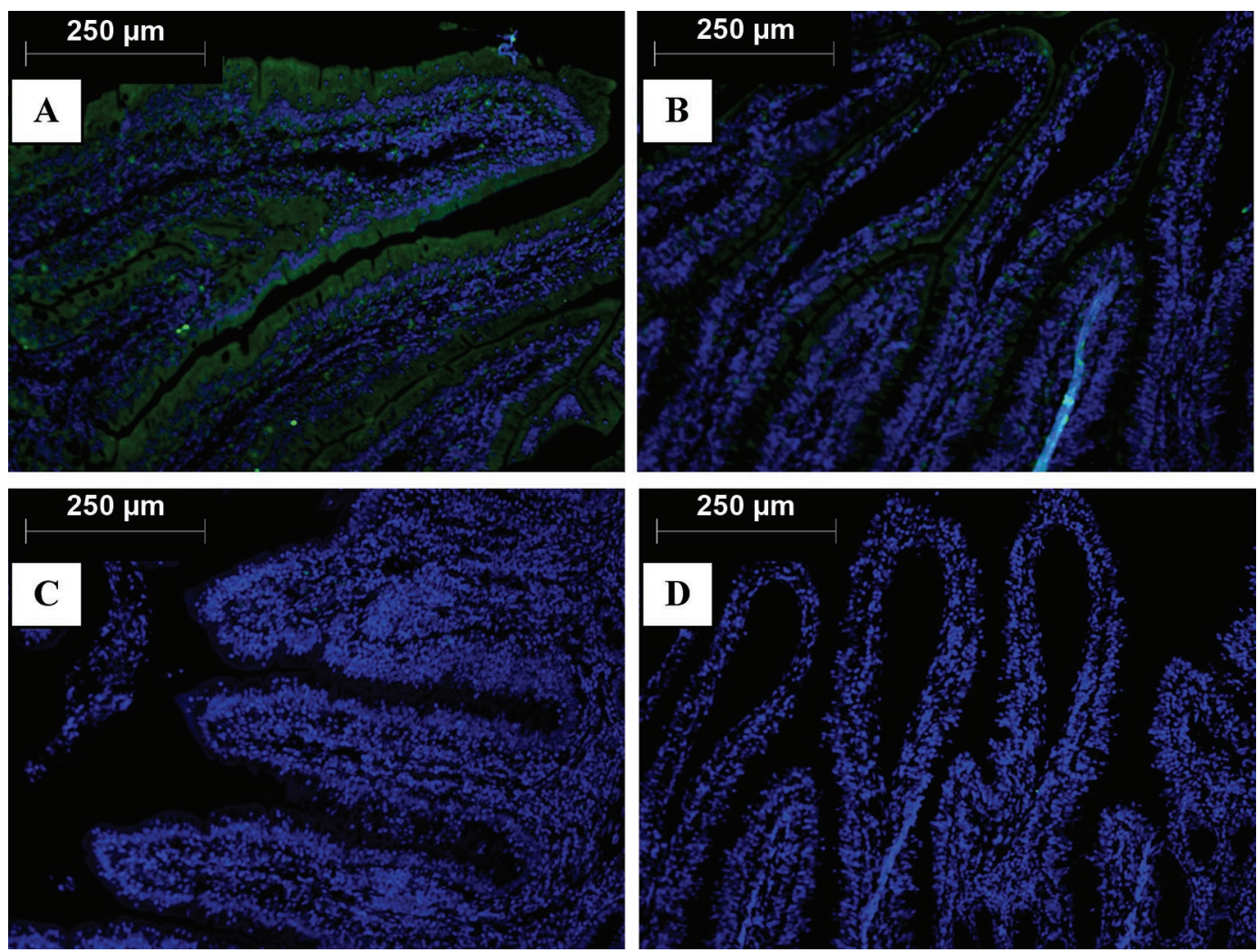

Figure 6. Representative image of proliferating cell nuclear antigen (PCNA) protein intensity in jejunum of a pair-fed control (PF; A) and a cow administered gamma-secretase inhibitor (GSI; B). Negative controls were primary antibody omitted (C) and IgG serum in place of primary antibody (D). Nuclear stain is blue and PCNA stain is green.

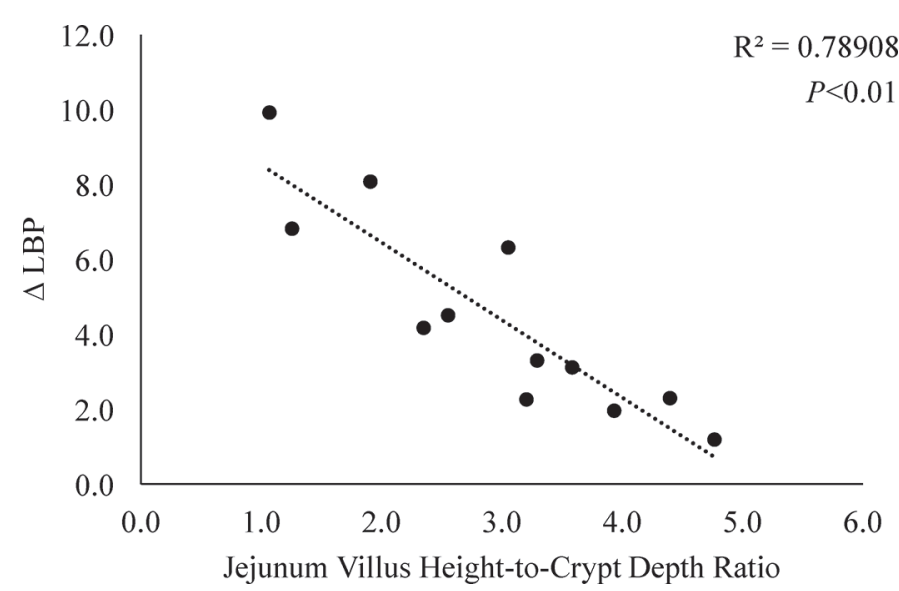

Figure 7. Correlation between the jejunum villus height-to-crypt depth ratio and the change in circulating LPS-binding protein (LBP; period 2 d 5 to 7 average minus the period 1 average). Analysis includes the combination of cows administered $1.5 \mathrm{mg} / \mathrm{kg}$ of BW gamma-secretase inhibitor (GSI) $2 \times / \mathrm{d}$ and cows pair-fed to GSI treatment and administered $1 \mathrm{~L}$ of saline $2 \times / \mathrm{d}$.

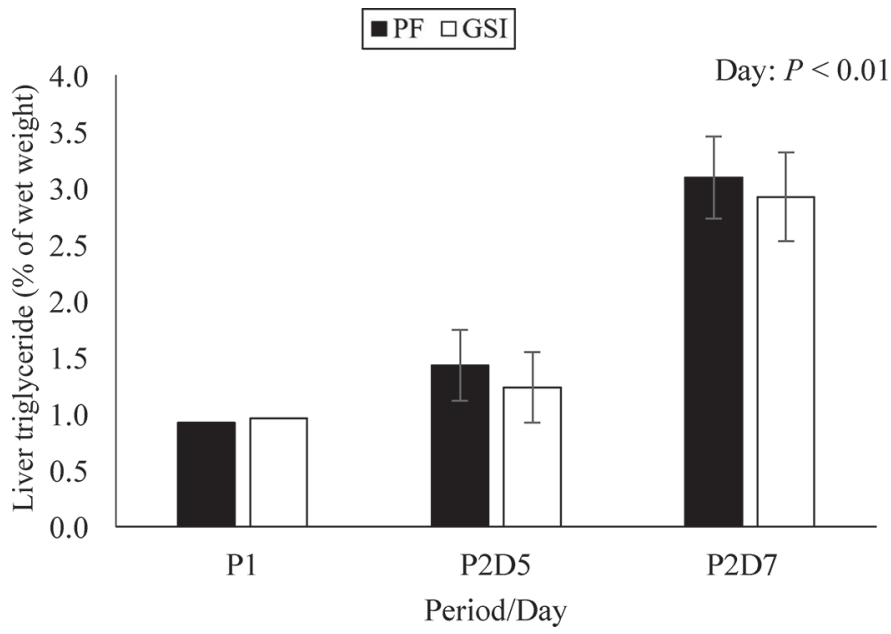

Figure 8. Effects of gamma-secretase inhibitor (GSI) or pair-feeding $(\mathrm{PF})$ on liver triglyceride as a percentage of wet weight. Due to logistical constraints, animals were killed on the same calendar day (P2 d 7 and P2 d 8 for PF and GSI animals, respectively). Values for $\mathrm{P} 1$ represent the period 1 average that was statistically used as a covariate. Results are expressed as LSM \pm SEM. 
Table 3. Effects of gamma-secretase inhibitor (GSI) or pair-feeding $(\mathrm{PF})$ on liver and spleen measurements postmortem and BW change

\begin{tabular}{|c|c|c|c|c|}
\hline \multirow[b]{2}{*}{ Item } & \multicolumn{2}{|c|}{ Treatment } & \multirow[b]{2}{*}{ SEM } & \multirow{2}{*}{$\frac{P \text {-value }}{\text { Treatmen }}$} \\
\hline & $\mathrm{PF}^{1}$ & $\mathrm{GSI}^{2}$ & & \\
\hline \multicolumn{5}{|l|}{ Liver } \\
\hline Weight (kg) & 9.5 & 10.6 & 0.5 & 0.19 \\
\hline$\%$ of BW & 1.6 & 1.8 & 0.1 & 0.42 \\
\hline Moisture (\%) & 68.6 & 71.0 & 1.0 & 0.14 \\
\hline \multicolumn{5}{|l|}{ Spleen } \\
\hline Weight (kg) & 1.20 & 1.05 & 0.05 & 0.73 \\
\hline$\%$ of BW & 0.18 & 0.16 & 0.01 & 0.28 \\
\hline \multicolumn{5}{|l|}{ BW } \\
\hline BW change ${ }^{3}(\mathrm{~kg})$ & -48.2 & -65.2 & 17.7 & 0.53 \\
\hline
\end{tabular}

${ }^{1}$ Cows pair-fed to gamma-secretase inhibitor treatment and administered $1 \mathrm{~L}$ of saline twice daily.

${ }^{2}$ Cows administered $1.5 \mathrm{mg} / \mathrm{kg}$ of BW gamma-secretase inhibitor twice daily.

${ }^{3}$ Over duration of treatment administration.

multiple heat-stressed species (Baumgard and Rhoads, 2013). Although they tended to have decreased NEFA concentrations at the end of P2, GSI-administered cows had a higher peak BHB relative to PF controls (124 vs. $81 \%$ increase from baseline, respectively). Interestingly, during the periparturient period, NEFA and BHB are not well correlated, and dairy cows diagnosed with ketosis have increased BHB levels despite similar NEFA concentrations (McCarthy et al., 2015; Zhang et al., 2016). Similarly, BHB is elevated in heat-stressed pigs despite a blunted response to lipolytic signals (Sanz Fernandez et al., 2015). Reasons for discordant patterns in NEFA and BHB are not clear, but increased circulating NEFA certainly cannot fully explain increased circulating BHB observed in GSI-treated cows. Despite marked treatment differences in circulating NEFA, liver triglyceride content increased similarly in both treatments, from what is considered "normal" during P1 to "mildly fatty" at sacrifice (Bobe et al., 2004). Incidentally, intestinal endotoxin infiltration contributes to hepatic steatosis (Ilan, 2012), and fatty liver is characteristic of both ketotic and heat-stressed transitioning dairy cows (Bobe et al., 2004; Bernabucci et al., 2010). Thus, it is not surprising GSI-infused cows had increased liver fat content despite $\sim 40 \%$ less circulating NEFA.

To our knowledge, this was the first study using GSI in a ruminant model. Therefore, our understanding of its direct influence on metabolic or endocrine systems is limited. Potential toxicity issues arise with GSI due to their inhibition of Notch cleavage, which is associated with alteration of lymphopoiesis in addition to intestinal toxicity (Wong et al., 2004). However, clinical trials for the specific GSI used in the present study have been conducted successfully in mice, dogs, and guinea pigs with few negative side effects (Hyslop et al., 2004; May et al., 2004; Lanz et al., 2006), and multiple human studies have been conducted by Siemers et al. (2005, 2006, 2007). Furthermore, goblet cell metaplasia may have been a limitation of our study, because increased mucus production may have partially limited bacterial translocation into portal and systemic circulation. However, due to the temporal increase in both circulating biomarkers of leaky gut and metabolic alterations, we consider this unlikely. Finally, our experimental design was complicated by the fact that both treatments negatively affected intestinal health during P2. Fortunately, neither treatment was implemented during P1 and each treatment's repeatedly measured parameters can be compared with its respective baseline value. Regrettably, this type of comparison cannot be accomplished for the intestinal morphology and organ data, because these variables were measured only at sacrifice. However, the detrimental effect of GSI on jejunal intestinal morphology (coupled with differences in LBP and insulin), despite similar feed restriction to the controls, indicated a more severe effect of GSI on intestinal integrity than feed restriction alone.

\section{CONCLUSIONS}

Administering GSI appeared to induce intestinal damage and compromise intestinal permeability. This reduced barrier integrity had production, metabolic, and inflammatory consequences, including decreased DMI, decreased milk yield, hyperinsulinemia, increased circulating ketones, and increased acute phase proteins. Further, feed restriction appeared to directly cause intestinal barrier dysfunction. We now have strong evidence to suggest that intestinal barrier dysfunction directly affects traditional production, metabolic, and inflammatory parameters, and many of these changes are strikingly similar to the phenotypes observed in both heat-stressed and ketotic dairy cows.

\section{ACKNOWLEDGMENTS}

This study was supported, in part, by Elanco Animal Health (Greenfield IN).

\section{REFERENCES}

Abuajamieh, M., S. K. Kvidera, M. V. Sanz Fernandez, A. Nayeri, N. C. Upah, E. A. Nolan, S. M. Lei, J. M. DeFrain, H. B. Green, K. M. Schoenberg, W. E. Trout, and L. H. Baumgard. 2016. Inflammatory biomarkers are associated with ketosis in periparturient Holstein cows. Res. Vet. Sci. 109:81-85.

AOAC International. 1995. AOAC official method 972.16: Fat, lactose, protein, and solids in milk. Mid-infrared spectroscopic method. Pages 23-26 in Official Methods of Analysis. 16th ed. Vol. 2. AOAC International, Arlington, VA. 
Bargiggia, S., G. Maconi, M. Elli, P. Molteni, S. Ardizzone, F. Parente, I. Todaro, S. Greco, G. Manzionna, and G. Bianchi Porro. 2003. Sonographic prevalence of liver steatosis and biliary tract stones in patients with inflammatory bowel disease: Study of 511 subjects at a single center. J. Clin. Gastroenterol. 36:417-420.

Bauman, D. E., and W. B. Currie. 1980. Partitioning of nutrients during pregnancy and lactation: A review of mechanisms involving homeostasis and homeorhesis. J. Dairy Sci. 63:1514-1529.

Baumgard, L. H., and R. P. Rhoads. 2013. Effects of heat stress on postabsorptive metabolism and energetics. Annu. Rev. Anim. Biosci. 1:7.1-7.27.

Baumgard, L. H., W. J. Weber, H. Chester-Jones, L. B. Hansen, G. W. Kazmer, S. A. Zinn, and B. A. Crooker. 2002. Growth hormone response to growth hormone releasing factor by Holstein calves from genetic lines selected for milk yield. J. Dairy Sci. 85:2529-2540.

Bernabucci, U., N. Lacetera, L. H. Baumgard, R. P. Rhoads, B. Ronchi, and A. Nardone. 2010. Metabolic and hormonal acclimation to heat stress in domesticated ruminants. Animal 4:1167-1183.

Bobe, G., J. W. Young, and D. C. Betiz. 2004. Invited review: Pathology, etiology, prevention, and treatment of fatty liver in dairy cows. J. Dairy Sci. 87:3105-3124.

Boudry, G., V. Péron, I. Le Huërou-Luron, J. P. Lallès, and B. Sève. 2004. Weaning induces both transient and long-lasting modifications of absorptive, secretory, and barrier properties of piglet intestine. J. Nutr. 134:2256-2262.

Ceciliani, F., J. J. Ceron, P. D. Eckersall, and H. Sauerwein. 2012. Acute phase proteins in ruminants. J. Proteomics 75:4207-4231.

Cheng, H., and C. P. Leblond. 1974. Origin, differentiation and renewal of the four main epithelial cell types in the mouse small intestine. I. Columnar cell. Am. J. Anat. 141:461-479.

De Strooper, B., W. Annaert, P. Cupers, P. Saftig, K. Craessaerts, J. S. Mumm, E. H. Schroeter, V. Schrijvers, M. S. Wolfe, W. J. Ray, A. Goate, and R. Kopan. 1999. A presenilin-1-dependent gammasecretase-like protease mediates release of Notch intracellular domain. Nature 398:518-522.

Draper, L. R., L. A. Gyure, J. G. Hall, and D. Robertson. 1983. Effect of alcohol on the integrity of the intestinal epithelium. Gut 24:399-404.

Emmanuel, D. G., K. L. Madsen, T. A. Churchill, S. M. Dunn, and B. N. Ametaj. 2007. Acidosis and lipopolysaccharide from Escherichia coli B:055 cause hyperpermeability of rumen and colon tissues. J. Dairy Sci. 90:5552-5557.

Ford, R. P., I. S. Menzies, A. D. Phillips, J. A. Walker-Smith, and M. W. Turner. 1985. Intestinal sugar permeability: Relationship to diarrhoeal disease and small bowel morphology. J. Pediatr. Gastroenterol. Nutr. 4:568-574.

Hyslop, P. A., P. C. May, J. E. Audia, D. O. Calligaro, C. L. McMillian, C. O. Garner, J. W. Cramer, B. D. Gitter, W. J. Porter, and J. S. Nissen. 2004. Reduction in A-Beta 1-40 and A $\beta$-Beta 1-42 in CSF and plasma in the beagle dog following acute oral dosing of the gamma-secretase inhibitor, LY450139. Neurobiol. Aging 25(Suppl. 2):S147. (Abstr.)

Ilan, Y. 2012. Leaky gut and the liver: A role for bacterial translocation in nonalcoholic steatohepatitis. World J. Gastroenterol. 18:2609-2618.

Jacobsen, S., T. Toelboell, and P. H. Andersen. 2005. Dose dependency and individual variability in selected clinical, haematological and blood biochemical responses after systemic lipopolysaccharide challenge in cattle. Vet. Res. 36:167-178.

Khafipour, E., D. O. Krause, and J. C. Plaizier. 2009. A grain-based subacute ruminal acidosis challenge causes translocation of lipopolysaccharide and triggers inflammation. J. Dairy Sci. 92:10601070.

Kisielinski, K., S. Willis, A. Prescher, B. Klosterhalfen, and V. Schumpelick. 2002. A simple new method to calculate small intestine absorptive surface in the rat. Clin. Exp. Med. 2:131-135.

Kvidera, S. K., E. A. Horst, M. Abuajamieh, E. J. Mayorga, M. V. Sanz Fernandez, and L. H. Baumgard. 2017. Glucose requirements of an activated immune system in lactating Holstein cows. J. Dairy Sci. 100:2360-2374. https://doi.org/10.3168/jds.2016-12001.
Kvidera, S. K., E. A. Horst, M. Abuajamieh, E. J. Mayorga, M. V. Sanz Fernandez, and L. H. Baumgard. 2016. Technical note: A procedure to estimate glucose requirements of an activated immune system in steers. J. Anim. Sci. 94:4591-4599.

Lang, C. H., C. Dobrescu, and K. Mészáros. 1990. Insulin-mediated glucose uptake by individual tissues during sepsis. Metabolism 39:1096-1107.

Lanz, T. A., M. J. Karmilowicz, K. M. Wood, N. Pozdnyakov, P. Du, M. A. Piotrowski, T. M. Brown, C. E. Nolan, K. E. Richter, J. E. Finley, Q. Fei, C. F. Ebbinghaus, Y. L. Chen, D. K. Spracklin, B. Tate, K. F. Geoghegan, L. F. Lau, D. D. Auperin, and J. B. Schachter. 2006. Concentration-dependent modulation of amyloidbeta in vivo and in vitro using the gamma-secretase inhibitor, LY-450139. J. Pharmacol. Exp. Ther. 319:924-933.

Lu, Y. C., W. C. Yeh, and P. S. Ohashi. 2008. LPS/TLR4 signal transduction pathway. Cytokine 42:145-151.

Ludvigsson, J. F., P. Elfström, U. Broomé, A. Ekbom, and S. M. Montgomery. 2007. Celiac disease and risk of liver disease: A general population-based study. Clin. Gastroenterol. Hepatol. 5:63-69. e1.

Mani, V., T. E. Weber, L. H. Baumgard, and N. K. Gabler. 2012. Growth and Development Symposium: Endotoxin, inflammation, and intestinal function in livestock. J. Anim. Sci. 90:1452-1465.

Maratou, E., G. Dimitriadis, A. Kollias, E. Boutati, V. Lambadiari, P. Mitrou, and S. A. Raptis. 2007. Glucose transporter expression on the plasma membrane of resting and activated white blood cells. Eur. J. Clin. Invest. 37:282-290.

May, P., Z. Yang, W. Li, P. Hyslop, E. Siemers, E. Boggs, and L. Boggs. 2004. Multi-compartmental pharmacodynamic assessment of the functional gamma-secretase inhibitor LY450139 in PDAPP transgenic and nontransgenic mice. Neurobiol. Aging 25(Suppl. 2):S65. (Abstr.)

McCarthy, M. M., S. Mann, D. V. Nydam, T. R. Overton, and J. A. McArt. 2015. Short communication: Concentrations of nonesterified fatty acids and $\beta$-hydroxybutyrate in dairy cows are not well correlated during the transition period. J. Dairy Sci. 98:6284-6290.

McGowan, C. E., P. Jones, M. D. Long, and A. S. Barritt. 2012. Changing shape of disease: Nonalcoholic fatty liver disease in Crohn's disease - A case series and review of the literature. Inflamm. Bowel Dis. 18:49-54.

McGuinness, O. P. 2005. Defective glucose homeostasis during infection. Annu. Rev. Nutr. 25:9-35.

Milano, J., J. McKay, C. Dagenais, L. Foster-Brown, F. Pognan, R. Gadient, R. T. Jacobs, A. Zacco, B. Greenberg, and P. J. Ciaccio. 2004. Modulation of notch processing by gamma-secretase inhibitors causes intestinal goblet cell metaplasia and induction of genes known to specify gut secretory lineage differentiation. Toxicol. Sci. $82: 341-358$

Minuti, A., S. Ahmed, E. Trevisi, F. Piccioli-Cappelli, G. Bertoni, N. Jahan, and P. Bani. 2014. Experimental acute rumen acidosis in sheep: Consequences on clinical, rumen, and gastrointestinal permeability conditions and blood chemistry. J. Anim. Sci 92:3966-3977.

Moeser, A. J., C. V. Klok, K. A. Ryan, J. G. Wooten, D. Little, V. L. Cook, and A. T. Blikslager. 2007. Stress signaling pathways activated by weaning mediate intestinal dysfunction in the pig. Am. J. Physiol. Gastrointest. Liver Physiol. 292:G173-G181.

Murphy, K. 2012. The mucosal immune system. Pages 465-507 in Janeway's Immunobiology. 8th ed. Garland Science, New York, NY.

National Research Council. 2001. Nutrient Requirements of Dairy Cattle. 7th rev. ed. Natl. Acad. Press, Washington, DC.

Obata, Y., D. Takahashi, M. Ebisawa, K. Kakiguchi, S. Yonemura, T. Jinnohara, T. Kanaya, Y. Fujimura, M. Ohmae, K. Hase, and H. Ohno. 2012. Epithelial cell-intrinsic Notch signaling plays an essential role in the maintenance of gut immune homeostasis. J. Immunol. 188:2427-2436.

Okamoto, R., K. Tsuchiya, Y. Nemoto, J. Akiyama, T. Nakamura T. Kanai, and M. Watanabe. 2009. Requirement of Notch activation during regeneration of the intestinal epithelia. Am. J. Physiol. Gastrointest. Liver Physiol. 296:G23-G35. 
Palsson-McDermott, E. M., and L. A. O'Neill. 2013. The Warburg effect then and now: From cancer to inflammatory diseases. BioEssays 35:965-973.

Pearce, S. C., V. Mani, T. E. Weber, R. P. Rhoads, J. F. Patience, L. H. Baumgard, and N. K. Gabler. 2013. Heat stress and reduced plane of nutrition decreases intestinal integrity and function in pigs. J. Anim. Sci. 91:5183-5193.

Rhoads, R. P., S. R. Sanders, L. Cole, M. Skrzypek, T. Elsasser, G. C. Duff, R.J. Collier, and L. H. Baumgard. 2009. Effects of heat stress on glucose homeostasis and metabolic response to an endotoxin challenge in Holstein steers. J. Anim. Sci. 87(E-Suppl. 2):78. (Abstr.)

Rodriguez, P., N. Darmon, P. Chappuis, C. Candalh, M. A. Blaton, C. Bouchaud, and M. Heyman. 1996. Intestinal paracellular permeability during malnutrition in guinea pigs: Effect of high dietary zinc. Gut 39:416-422.

Sanz Fernandez, M. V., J. S. Johnson, M. Abuajamieh, S. K. Stoakes, J. T. Seibert, L. Cox, S. Kahl, T. H. Elsasser, J. W. Ross, S. C. Isom, R. P. Rhoads, and L. H. Baumgard. 2015. Effects of heat stress on carbohydrate and lipid metabolism in growing pigs. Physiol. Rep. 3:e12315.

Siemers, E., M. Skinner, R. A. Dean, C. Gonzales, J. Satterwhite, M. Farlow, D. Ness, and P. C. May. 2005. Safety, tolerability, and changes in amyloid beta concentrations after administration of a gamma-secretase inhibitor in volunteers. Clin. Neuropharmacol. 28:126-132.

Siemers, E. R., R. A. Dean, S. Friedrich, L. Ferguson-Sells, C. Gonzales, M. R. Farlow, and P. C. May. 2007. Safety, tolerability, and effects on plasma and cerebrospinal fluid amyloid-beta after inhibition of gamma-secretase. Clin. Neuropharmacol. 30:317-325.

Siemers, E. R., J. F. Quinn, J. Kaye, M. R. Farlow, A. Porsteinsson, P. Tariot, P. Zoulnouni, J. E. Galvin, D. M. Holtzman, D. S. Knopman, J. Satterwhite, C. Gonzales, R. A. Dean, and P. C. May. 2006. Effects of a gamma-secretase inhibitor in a randomized study of patients with Alzheimer disease. Neurology 66:602-604.

Skidmore, A., A. Brand, and C. Sniffen. 1996. Monitoring milk production: Defining preset targets and execution. Pages 223-262 in Herd Health and Production Management in Dairy Practice. A. Brand, J. Noordhuizen, and Y. Schukken, ed. Wageningen Academic Publishers, Wageningen, the Netherlands.

Stoakes, S. K., E. A. Nolan, M. Abuajamieh, M. V. Sanz Fernandez, and L. H. Baumgard. 2015b. Estimating glucose requirements of an activated immune system in growing pigs. J. Anim. Sci. 93(ESuppl. S3):634. (Abstr.)

Stoakes, S. K., E. A. Nolan, D .J. Valko, M. Abuajamieh, J. T. Seibert, M. V. Sanz Fernandez, P. J. Gorden, H. B. Green, K. M. Schoen- berg, W. E. Trout, and L. H. Baumgard. 2015a. Characterizing the effect of feed restriction on biomarkers of leaky gut. J. Dairy Sci. 98(E-Suppl. 2):274. (Abstr.)

van der Heijden, P. J., W. Stok, and A. T. Bianchi. 1987. Contribution of immunoglobulin-secreting cells in the murine small intestine to the total 'background' immunoglobulin production. Immunology $62: 551-555$.

van der Hulst, R. R., M. F. von Meyenfeldt, B. K. van Kreel, F. B. Thunnissen, R. J. Brummer, J. W. Arends, and P. B. Soeters. 1998. Gut permeability, intestinal morphology, and nutritional depletion. Nutrition 14:1-6.

van Es, J. H., M. E. van Gijn, O. Riccio, M. van den Born, M. Vooijs, H. Begthel, M. Cozijnsen, S. Robine, D. J. Winton, F. Radtke, and H. Clevers. 2005. Notch/gamma-secretase inhibition turns proliferative cells in intestinal crypts and adenomas into goblet cells. Nature 435:959-963.

Vernon, R. G. 1992. Effects of diet on lipolysis and its regulation. Proc. Nutr. Soc. 51:397-408.

Waldron, M. R., A. E. Kulick, A. W. Bell, and T. R. Overton. 2006. Acute experimental mastitis is not causal toward the development of energy-related metabolic disorders in early postpartum dairy cows. J. Dairy Sci. 89:596-610

Welsh, F. K., S. M. Farmery, K. MacLennan, M. B. Sheridan, G. R. Barclay, P. J. Guillou, and J. V. Reynolds. 1998. Gut barrier function in malnourished patients. Gut 42:396-401.

Wheelock, J. B., R. Rhoads, M. Vanbaale, S. Sanders, and L. Baumgard. 2010. Effects of heat stress on energetic metabolism in lactating Holstein cows. J. Dairy Sci. 93:644-655.

Wong, G. T., D. Manfra, F. M. Poulet, Q. Zhang, H. Josien, T. Bara, L. Engstrom, M. Pinzon-Ortiz, J. S. Fine, H. J. Lee, L. Zhang, G. A. Higgins, and E. M. Parker. 2004. Chronic treatment with the gamma-secretase inhibitor LY-411,575 inhibits beta-amyloid peptide production and alters lymphopoiesis and intestinal cell differentiation. J. Biol. Chem. 279:12876-12882.

Zhang, G., D. Hailemariam, E. Dervishi, S. A. Goldansaz, Q. Deng, S. M. Dunn, and B. N. Ametaj. 2016. Dairy cows affected by ketosis show alterations in innate immunity and lipid and carbohydrate metabolism during the dry off period and postpartum. Res. Vet. Sci. 107:246-256

Zhang, S., R. I. Albornoz, J. R. Aschenbach, D. R. Barreda, and G. B. Penner. 2013. Short-term feed restriction impairs the absorptive function of the reticulo-rumen and total tract barrier function in beef cattle. J. Anim. Sci. 91:1685-1695. 